09

\title{
Спектральная фотосенсибилизация оптической анизотропии в твердотельных пленках поли(винилциннамата)
}

\author{
(C) В.М. Козенков, ${ }^{1}$ А.А. Спахов, ${ }^{1,}$ В.В. Беляев, ${ }^{1,2}$ Д.Н. Чаусов, ${ }^{1}$ В.Г. Чигринов ${ }^{3}$ \\ ${ }^{1}$ Московский государственный областной университет, \\ 105005 Москва, Россия \\ 2 Российский университет дружбы народов, \\ 117198 Москва, Россия \\ ${ }^{3}$ Hong Kong University of Science and Technology, \\ Clear Water Bay Road, Kowloon, Hong Kong, China \\ ฯe-mail: aa.spakhov@mgou.ru
}

(Поступило в Редакцию 24 марта 2017 г.

В окончательной редакции 17 октября 2017 г.)

Исследована возможность и особенности формирования сенсибилизированной фото-индуцированной оптической анизотропии в аморфных пленках поли(винилциннамата) и его производного поли(винил-4-метоксициннамата) под действием поляризованного света, в том числе не поглощаемого самими макромолекулами полимера. Установлено, что эффект наведенной оптической анизотропии основан на передаче энергии электронного возбуждения от молекул донора (сенсибилизатора) к молекулам акцептора и протекает при фототопохимической бимолекулярной реакции циклизации циннаматных фрагментов в макромолекулах полимеров. Обнаруженная фотоиндуцированная анизотропия в твердых пленках поли(винилциннамата) и его производного поли(винил-4-метокси-циннамата) обеспечивает сенсибилизированную фотоориентацию низкомолекулярных термотропных жидких кристаллов.

DOI: $10.21883 /$ JTF.2018.04.45729.2263

\section{Введение}

Явление фотоиндуцированной оптической анизотропии (дихроизм поглощения и двулучепреломление) (ФИА) в исходно изотропных конденсированных средах, содержащих анизотропные фотохимически чувствительные молекулы, было обнаружено Вейгертом (F. Weigert) в 1919 г. и известно в настоящее время как эффект Вейгерта. Явление связано с анизотропной природой оптического излучения и обусловлено тем, что вероятность поглощения анизотропной молекулой пропорциональна квадрату косинуса угла между направлениями вектора электрического поля оптического излучения и ее дипольного момента перехода. Первоначально фотохимические реакции в таких твердотельных средах имели мономолекулярный характер в виде необратимых или обратимых (фотохромных) внутримолекулярных перестроек, или фотодиссоциаций при поглощении поляризованного излучения. Впервые таким фотоанизотропным материалом (ФАМ), проявляющим бимолекулярную фотохимическую реакцию, оказался фоточувствительный полимер из класса поли(винилциннамата).

Явление сенсибилизированного формирования ФИА в классических твердых аморфных пленках фоточувствительного полимера из класса поли(винилциннамата) (PVCi) [1,2] и его аналога поли(винил-4-метоксициннамата) (PVMCi) [3] широко используется в фотолитографии, голографии, интегральной, волоконной и поляризационной оптике, в системах оптической записи, хранения, обработки и защиты информации.
Считается, что при облучении УФ излучением бимолекулярная реакция фотодимеризации в твердотельных слоях является основным фотопроцессом, приводящим к формированию „сшитой“ пространственной полимерной сетки. Это сопровождается потерей растворимости пленок PVCi в органических растворителях в облученных участках, что очень важно для фотолитографических применений. Роль свободнорадикальной реакции и обратимой транс $\leftrightarrow$ цис фотоизомеризации в таких слоях считается второстепенной [4]. При этом в изотропной полимерной пленке, как и в растворе, квантовый выход реакции фотодимеризации не превышает 0.25 (в слоях кристаллической коричной кислоты он равен 1.4) [5].

В течение более 50 лет PVCi широко исследуется и применяется в фотолитографии в качестве негативного фоторезиста [5]. В настоящее время композиция на основе производных циннаматов в качестве фотоориентанта впервые внедрена фирмой Sharp (Япония) в технологии $\mathrm{UV}^{2} \mathrm{~A}$ [6] при производстве нового поколения ЖКдисплеев с повышенной контрастностью и яркостью экрана.

Целью настоящей работы является исследование формирования сенсибилизированной фотоиндуцированной оптической анизотропии в аморфных пленках поли(винилциннамата) и его производного поли(винил4-метокси-циннамата) под действием поляризованного света и установление физических механизмов этого процесса, что позволит повысить эффективность материалов в различных задачах оптики и оптической обработки информации. 


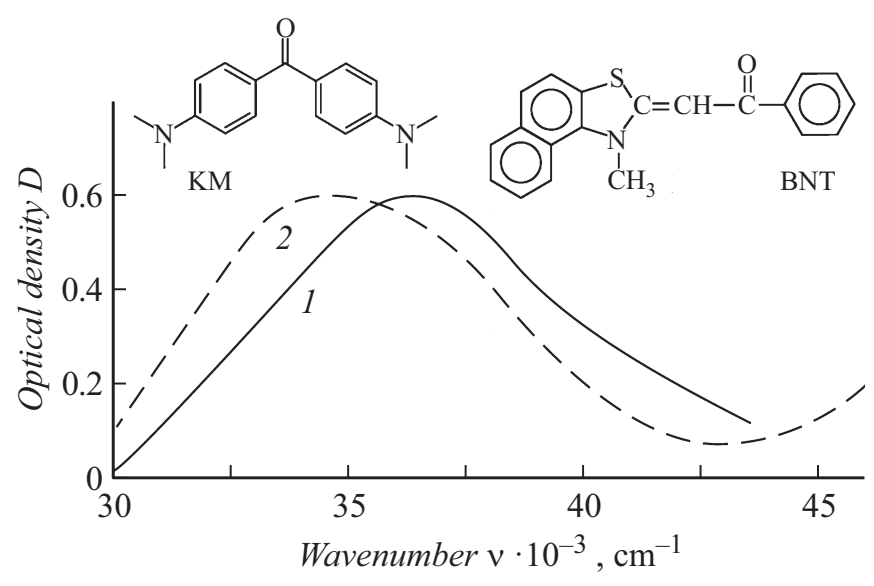

Рис. 1. Спектры поглощения пленок PVCi и PVMCi и химические формулы фотосенсибилизаторов.

\section{1. Эксперимент}

В качестве источника поляризованного активирующего излучения использовалась ртутная лампа сверхвысокого давления ДРШ-250 с электрической мощностью $250 \mathrm{~W}$ в сочетании со стеклянными светофильтрами и призмами Глана-Томпсона в качестве линейных поляризаторов. Линзовая система использовалась для формирования параллельного пучка поляризованного активирующего излучения. Измерение кинетики фотоиндуцированного двойного лучепреломления (ДЛП) осуществлялось в области прозрачности образца, при использовании $\mathrm{He}-\mathrm{Ne}$-лазера с длиной волны $\lambda_{\text {trial }}=632.8 \mathrm{~nm}$ по методике, описанный ранее в нашей работе [7].

Исходные полимеры PVCi и PVMCi использовались ранее в качестве фотоанизатропных материалов и фотоориентирующих слоев термотропных ЖК [8]. Степень этерификации составляла $\sim 99 \%$. Область собственной чувствительности образцов совпадает со спектрами их поглощения с длинноволновой границей $370 \mathrm{~nm}$, которые приведены на рис. 1.

В качестве оптических сенсибилизаторов использовали (4, 4'-бис $(N, N$-диметиламино)бензофенон), более известный как сенсибилизатор Кетона Михлеpa $(\mathrm{KM}) \quad\left(T_{\text {melt }}=173^{\circ} \mathrm{C}\right.$ с максимумом спектра поглощения при длине волны $\lambda=355 \mathrm{~nm}$ ) и нафтотиазолин (2-бензоилметилен-3 метил- $\beta$-нафтотиазолин) (BNT) $\left(T_{\text {melt }}=220^{\circ} \mathrm{C}\right.$ с максимумом поглощения при $\lambda=260$ и $400 \mathrm{~nm})$. Их химические формулы приведены на рис. 1.

\section{2. Результаты и обсуждение}

Начальные участки кинетики формирования ФИА в слоях PVMCi, сенсибилизированных нафтотиазолином $\mathrm{BNT}$, приведены на рис. 2 для разных длин волн $\lambda_{\exp }=436,405$ и $365 \mathrm{~nm}$. Излучение с длинами волн 436, $405 \mathrm{~nm}$ поглощается только молекулами BNT, причем вторая длина волны находится около максимума поглощения BNT ( $400 \mathrm{~nm})$. Как видно из рис. $2, a, b$, в слоях PVMCi без сенсибилизатора ФИА не формируется (кривая 1). При активации на длине волны $365 \mathrm{~nm}$, где УФ излучение поглощается обеими компонентами, скорость ее образования имеет максимальное значение в отсутствии сенсибилизатора (рис. 2, , кривая 1). При этом с увеличением концентрации сенсибилизатора скорость образования ФИА существенно падает (кривая 2 и 5). Этот эффект имеет обратную тенденцию при длине волны $436 \mathrm{~nm}$, проявляющимся в значительном увеличении фотоиндуцированного ДЛП с ростом концентрации BNT в слое PVMCi (рис. 2, $a$, кривые 2 и 5). Для излучения $405 \mathrm{~nm}$ эффект увеличения скорости наведения ДЛП (рис. 2, $b$, кривые 2 и 3) наблюдается только при малых концентрациях $\sim 0.5-1.0 \%$ и падает при дальнейшем увеличении (рис. $2, b$, кривые 4 и 5 ).

Как следует из рис. 2 эффективность спектральной сенсибилизации ФИА в слоях поли(винилциннаматов) в значительной степени определяется как длиной волны активирующего излучения $\lambda_{\exp }$, так и концентрацией сенсибилизатора в слое.

Несенсибилизированный слой PVCi (рис. 3, кривая 1), как и аналогичный слой PVMCi, не поглощает на длине волны более $400 \mathrm{~nm}$ (рис. 1) и соответственно не проявляет эффекта ФИА при действии излучения с $\lambda_{\exp }=405 \mathrm{~nm}$. Он возникает при введении сенсибилизатора, причем скорость и величина наведенной фазовой

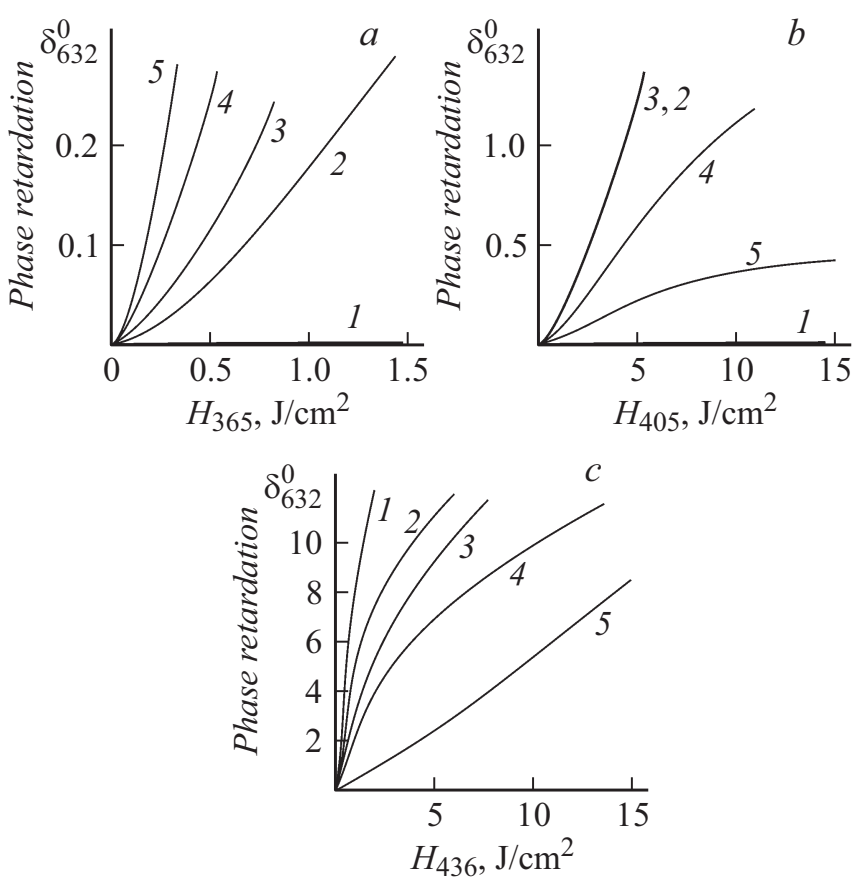

Рис. 2. Начальные участки кинетики фотоиндуцированной фазовой задержки $\delta_{632}$ в слое PVMCi с примесью BNT при концентрациях: $1-0 ; 2-0.5 ; 3-1.0 ; 4-2.0 ; 5-4.0 \%$ как функции энергии $H_{\exp }$ с излучением $\lambda_{\exp }-(a) 436 \mathrm{~nm}$, (b) $405 \mathrm{~nm}$ и (c) $365 \mathrm{~nm}$. 


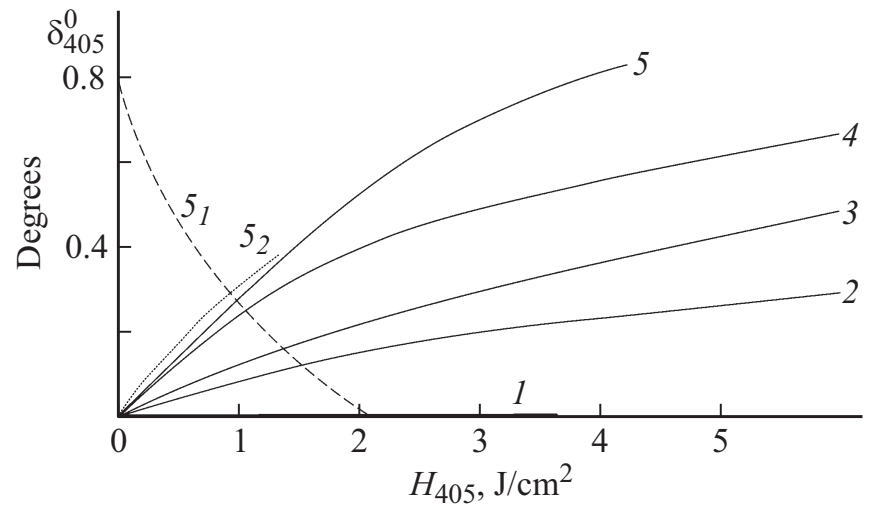

Рис. 3. Кинетики фотоиндуцированной фазовой задержки $\delta_{405}$ в слое РVCі с примесью КМ при концентрациях: $1-0 ; 2-$ $0.5 ; 3-1.0 ; 4-2.0 ; 5-4.0 \%$ как функции энергии $H_{\exp }$ с излучением $\lambda_{\exp }=405 \mathrm{~nm}$.

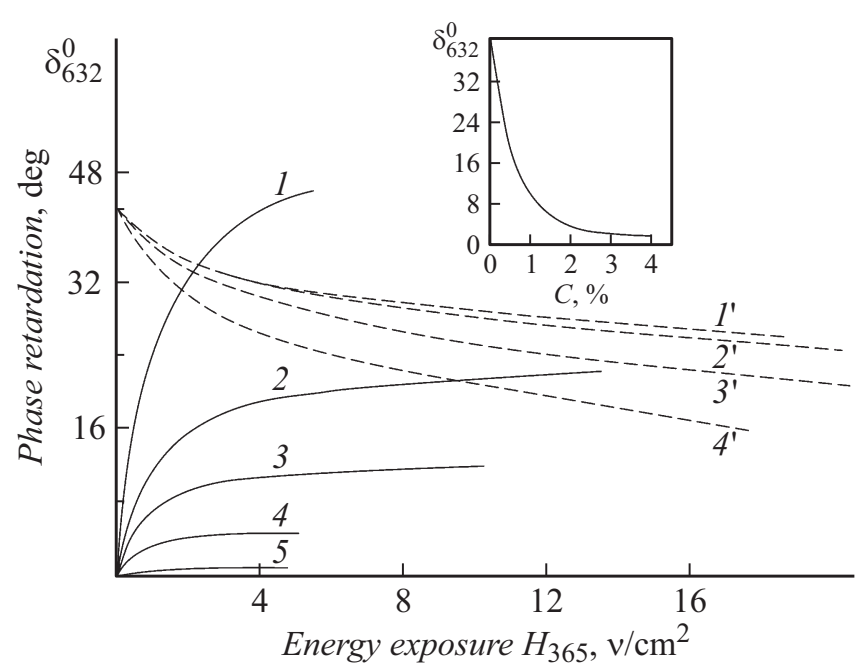

Рис. 4. Наведение (с кривой 1 по 4) и темновая релаксация (с кривой $1^{\prime}$ по $4^{\prime}$ ) фазовой задержки $\delta_{632}$ в слое PVMCi c примесью BNT при концентрациях: $1-0.5 ; 2-1.0 ; 3-2.0$; $4-4.0 \%$. Кривая $5-1.0 \%-$ BNT в ПММА. На вставке показаны максимально достигаемые величины $\delta_{632}$ для слоев с различной концентрацией BNT.

задержки $\delta_{632}$ возрастает с увеличением концентрации КМ в слое.

Наведенная анизотропия может быть оптически „стерта“, как показано на рис. 3, кривая 5, и восстановлена заново (рис. 3 , кривые $5_{1}$ и $5_{2}$ ).

В пленке PVMCi без сенсибилизатора при действии излучения с $\lambda_{\exp }>400 \mathrm{~nm}$ (рис. $2, a, b$, кривая 1 ) эффект ФИА отсутствует, т. е. каждый из реагирующих компонентов индивидуально не проявляет эффекта ФИА. PVCi не поглощает на длине волны более $405 \mathrm{~nm}$, а молекулы сенсибилизатора КМ фотохимически стабильны.

К сожалению, оптические сенсибилизаторы оказывают десенсибилизирующее действие в спектральной области поглощения поли(винилциннаматов) при формировании в них фотоиндуцированного ДЛП, что показано на вставке к рис. 4. При введении сенсибилизатора максимально достигаемая величина $\delta_{632}$ уменьшается с ростом концентрации.

Схожая тенденция наблюдается в слоях PVMCi, сенсибилизированных нафтотиазолином BNT при их облучении поляризованным излучением с $\lambda_{\exp }=365 \mathrm{~nm}$ на краю спектра поглощения PVMCi (рис. 4, кривые 1-4). При этом сам BNT не проявляет заметного ДЛП (рис. 4, кривая 5) в системе с фотохимически стабильным полиметилметакрилатом (ПММА). Небольшой эффект ФИА, наблюдаемый в пленках ПММА с BNT, может быть обусловлен обратимыми фотохимическими процессами в BNT. Прекращение облучения приводит к некоторому спаду ДЛП (рис. 4, кривые $1^{\prime}-4^{\prime}$ ), который может быть отнесен к релаксации внутренних напряжений. Заметное увеличение скорости и величины темновой релаксации наведенного ДЛП связано с некоторым „пластифицирующим“ действием сенсибилизатора, рост которого увеличивается с концентрацией последнего.
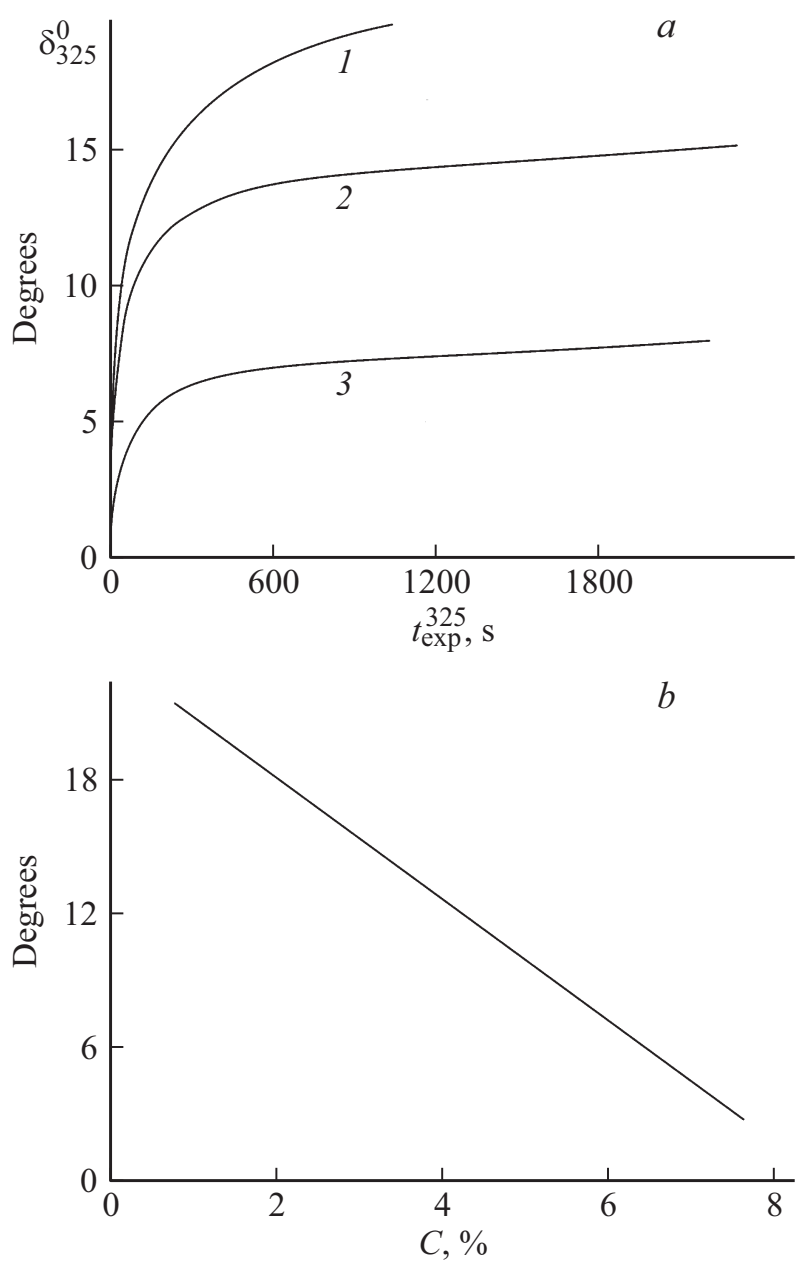

Рис. 5. Кинетики фотоиндуцированной фазовой задержки $\delta_{325}$ как функции времени экспонирования $t_{\text {exp }}$ излучением с $\lambda_{\text {exp }}=325 \mathrm{~nm}$ в слоях PVСі с примесью фотоинициатора КМ: $1-2.0 ; 2-4.0$ и $3-6.0 \%(a)$; максимально достигаемые величины $\delta_{325}$ для слоев с различной концентрацией КМ при облучении излучением с $\lambda_{\exp }=325 \mathrm{~nm}(b)$. 


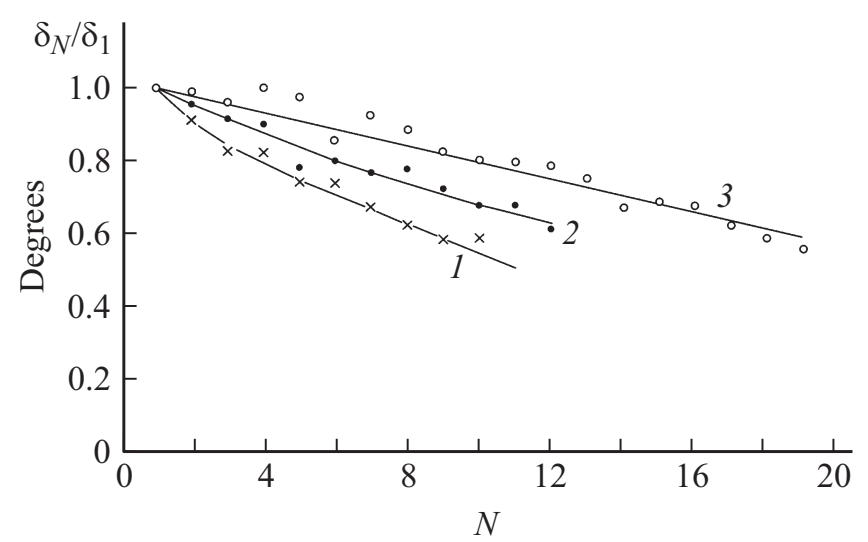

Рис. 6. Зависимость относительной величины фотоиндуцированной фазовой задержки от числа циклов $(N)$ оптического „наведения“ и „стирания“ в слоях РVCi с примесью фотоинициатора КМ: $1-2.0 ; 2-4.0$ и $3-6.0 \%$ при облучении излучением с $\lambda_{\exp }=365 \mathrm{~nm}$.

Аналогичные эффекты наблюдаются и при облучении сенсибилизированных слоев PVCi на длине волны излучения непрерывного $\mathrm{He}-\mathrm{Cd}$-лазера с $\lambda_{\exp }=325 \mathrm{~nm}$ (рис. 5).

Как и в слоях PVCi без фотоинициатора [9-11], его наличие не препятствует многократному циклу оптического „стирания“ и повторного наведения ФИА. Более того, увеличение его концентрации увеличивает цикличность, как это видно из рис. 6 .

\section{Заключение}

Таким образом, приведенные на рис. 2-6 экспериментальные кривые показывают возможность формирования ФИА в двухкомпонентной системе, состоящей из полимерной фотоструктурирующейся матрицы с растворенными в ней молекулами сенсибилизатора при действии поляризованного излучения, не поглощаемого матрицей. При этом эффект ФИА не наблюдается в такой полимерной матрице без сенсибилизатора при действии излучения того же спектрального состава, поскольку она не поглощает данное излучение.

Проведенные исследования показывают, что исходно изотропные аморфные слои сенсибилизированного PVCi и его аналога PVMCi проявляют эффект ФИА при воздействии излучения в коротковолновой области видимого спектра, не поглощаемого непосредственно самими макромолекулами. Кроме того, установлено, что эффект ФИА не наблюдается и в фотохимически инертных к этому и УФ излучению полимерных слоях с растворенными в них теми же молекулами сенсибилизатора. Однако, как и в слоях PVCi без сенсибилизатора, наведенная в них анизотропия термически неустойчива и исчезает при нагреве. Предельная величина и соответственно способность ориентировать ЖК в таких слоях уменьшаются.
Тем не менее можно предположить, что в результате безызлучательной колебательной релаксации энергии поглощенного фотохимически неактивного кванта излучения [12] с определенной вероятностью происходит трансляционная подвижка и угловая ориентационная перестройка ближайших молекул сенсибилизатора и циннаматных пар. Это, в свою очередь, может способствовать или формированию ФИА по фотофизическому механизму $[7,13]$, или увеличению квантового выхода „ $T-T^{\text {“ }}$ переноса энергии поглощенного кванта от сенсибилизатора на циннаматный фрагмент одной из молекул $\mathrm{PVCi}$ и бимолекулярной фототопохимической реакции циклизации молекул PVCi в целом.

Еще более успешные результаты могут быть достигнуты при спектральной сенсибилизации химически модифицированных слоев PVCi с приданием им жидкокристаллических свойств. В качестве такого альтернативного решения в [14-18] впервые были исследованы фотосшивающиеся ЖК полимеры с фотореактивными ЖК мезогенными циннамоильными и бифенильными группами в боковой цепи, в том числе при двухфотонной сенсибилизации [19]. Было установлено, что сенсибилизированная ФИА в таких полимерах не только термически устойчива, но даже усиливается при действии повышенных температур.

Следует отметить, что подобный эффект усиления, названный в [7] релаксацией „вверх“, ранее наблюдался во многих ФАМ на основе фотохимически стабильных веществ.

Работа выполнена при поддержке внутриуниверситетского научного гранта 2016 г. Государственного образовательного учреждения высшего образования Московской области Московского государственного областного университета (МГОУ).

\section{Список литературы}

[1] Robertson E., van Deusen W., Minsk L. // J. Appl. Polym. Sci. 1959. Vol. 2. P. 308.

[2] Minsk L., Smith J., van Deusen W., Wright J. // J. Appl. Polym. Sci. 1959. Vol. 2. P. 302-307.

[3] Козенков В.М., Кисилица П.П., Ганущак Н.И., Катышев Е.Г., Наумова Н.А., Орлова Т.Н., Обушак Н.Д., Шулев Ю.В. Поляризационно-чувствительный фотографический материал. SU 1769607 A1. 1995.

[4] Perny S., Barny P. Le, Delaire J., Beffeteau T., Sourisseau C., Dozov I., Forget S., Martinot-Lagarde P. // Liquid Crystals. 2000. Vol. 27. P. 329-340.

[5] Моро У. Микролитография. Принципы, методы, материалы. М.: Мир, 1990. 606 с.

[6] http://sharp-world.com/corporate/news/090916.html, Sharp to incorporate $\mathrm{UV}^{2}$ A Technology into production of LCD panels. 2009.

[7] Kozenkov V.M., Spakhov A.A., Chigrinov V.G., Belyaev V.V., Tumovskij G.D. // SID Digest. 2012. P-93. P. 1411-1414.

[8] Агранович В.М., Галанин М.Д. Перенос энергии электронного возбуждения в конденсированных средах. М.: Наука, 1978. C. 383 
[9] Квасников Е.Д., Козенков В.М., Барачевский В.А. // ДАН СССР. 1977. 237. С. 633-636.

[10] Козенков В.М., Катышев Е.Г., Барачевский В.А., Кисилища П.П., Наумова Н.А. // Журн. научн. и прикл. фотогр. и кинематогр. 1985. Т. 4. С. 281-286.

[11] Kozenkov V., Chigrinov V., Kwok H.S. // Mol. Cryst. Liq. Cryst. 2004. Vol. 409. P. 251-267.

[12] Басиев Т.T., Дорошенко М.Е., Осико В.В. // Письма в ЖЭТФ. 2000. Вып. 71. С. 14-19.

[13] Козенков В.М., Барачевский В.А. // Свойства светочувствительных материалов и их применение в голографии. Л.: Наука, 1987. С. 89-96.

[14] Верховская К.А., Ванников А.В., Гришина А.Д. и др. // ЖТФ. 2016. Т. 86. Вып. 7. С. 148-150.

[15] Белашов А.В., Бельтюкова Д.М., Васютинский О.С. и др. // Письма в ЖТФ. 2014. Т. 40. Вып. 24. С. 94-98.

[16] Александрова Е.Л., Светличный В.М., Матюшина Н.В. и др. // ФТП. 2014. Т. 48. Вып. 11. С. 1517-1520.

[17] Kawatsuki N., Kato K., Shiraku T., Tachibana T., Ono H. // Macromolecules. 2006. Vol. 39. P. 3245-3251.

[18] Furumi S., Ichimura K. // Phys. Chem. Chem. Phys. 2011. Vol. 13. P. 4919-4927.

[19] Kawatsuki N., Tachibana T., Kamada K. // Adv. Mater. 2005. Vol. 17. P. $1886-1890$. 